\title{
Reflection on Farmers' Participation in Rural Community Cultural Construction
}

\author{
Xiaoxia Zhang \\ School of Marxism, Changchun University of Science and Technology \\ Changchun 130022, China \\ E-mail: 1kzxx@cust.edu.cn \\ Yonggui Lu \\ College of Mechanical and Electric Engineering, Changchun University of Science and Technology \\ Changchun 130022, China \\ E-mail: luyonggui@cust.edu.cn
}

Received: June 19, 2011 Accepted: July 20, $2011 \quad$ doi:10.5539/ass.v7n9p240

\begin{abstract}
Farmers are the subject for rural community cultural construction. Development of rural community cultural construction can not go without participation of farmers. At present, there exist a lot of factors that impede farmers' participation in community cultural construction. Firstly, basic cultural facilities and occasions are lacking for participation of farmers. Secondly, farmers have no enough knowledge in community cultural construction and have relatively low autonomy in participation. Thirdly, the relatively low cultural quality of farmers also constrains the ability of farmers to participation in community cultural construction. This article puts forward several measures to promote farmers to participate in community cultural construction, such as, to strengthen community education, enhance the quality of farmers and intensify the enthusiasm and ability of farmers to participate; to enlarge capital investment to set up cultural facilities and occasions and to offer solid material foundations for farmers' participation; to cultivate positively community cultural organizations and to push forward farmers to participate in community cultural construction; to resort to community culture and elegant culture to enhance the rural cultural level and to absorb farmers to participate in community cultural construction.
\end{abstract}

Keywords: Rural community, Cultural Construction, Farmers' participation

Ever since the reform and opening up in China, with development of rural community cultural construction, importance of farmers to participate in rural community cultural construction becomes increasingly prominent. However, there exist a lot of impediments in farmers' participation in community cultural construction, which affects enthusiasm of farmers in participation. Without extensive participation of farmers, the condition that rural community cultural construction lags behind may not get fundamentally changed and the target of building a well-off society in an all-around way and building a new socialist countryside will also be difficult to be successfully realized. Thus, to attempt to explore an effective approach to promoting farmers to participate in rural community cultural construction has become a problem to be urgently resolved in boosting rural community cultural construction.

\section{The significant meaning of farmers' participation in rural community cultural construction}

For the time being, China is in the process of new rural construction, while as an important component of new rural construction, rural community cultural construction has significant meaning to boost coordinated rural economic and social development, which helps to push forward sustainable and rapid development of rural economy, promote industrialization and modernization of agriculture, keep rural social stability, promote rural spiritual civilization construction and prosper and enrich the spiritual and cultural life of the vast majority of farmers. "Fundamentally speaking, rural community cultural construction is the core of rural community construction and development, an indispensable part of rural socialist spiritual civilization, and also a component 
for construction of socialism culture with Chinese characteristics as well as an important means to push forward construction of rural socialist material civilization, political civilization and spiritual civilization. (Zhang Guifang, 2004)

The subject for rural community cultural construction is farmers. In order to strengthen rural community cultural construction, without extensive participation of farmers, it is unlikely to achieve efficiency in rural community cultural construction. At present, a lot of regions and areas are bringing culture to the countryside, which greatly enriches the spiritual and cultural life of the vast majority of rural farmers, but this is nothing more than a holiday feast, since it is neither culture surrounding farmers nor it is able to totally resolve the cultural hunger and thirst of farmers. In order to really satisfy the cultural demands of farmers, it is necessary to make culture take roots in farmers and germinate and thus become culture of farmers themselves. (Mu Yifei, 2005) Hence, the best method to let farmers enjoy culture is to enable farmers to become participants and creators of culture. That is to say, rural cultural construction should not only serve the farmers, more importantly, but should mobilize the enthusiasm of farmers in creating new culture and let farmers become the subject for new rural cultural construction.

\section{Analysis of relevant factors that impede farmers' participation in rural community cultural construction}

Although rural community cultural construction can not go without participation of the vast majority of farmers, considering the status quo of Chinese rural community cultural construction, there still exist a lot of negative factors that impede farmers' participation in current rural community cultural construction, which mainly include the following three aspects:

Firstly, basic cultural facilities and occasions are deficient in participation of farmers in rural community cultural construction. Rural cultural infrastructure is the basic condition for rural community cultural development. Nevertheless, the current rural cultural infrastructure is quite laggard and is in serious shortage. Township cultural stations have weak functions, with insufficient funds investment, and the library has a serious shortage of materials. Rural public cultural service system is not complete. Moreover, since the existing cultural infrastructure is lacking in management and its development and employment is limited, some cultural infrastructure performs practically no function at all. As a result of laggard infrastructure and lack of hardware support of occasions for holding cultural activities, corresponding material conditions are also deficient in farmers' participation, which also leads to slow development of rural cultural undertakings. The laggard situation of rural cultural infrastructure seriously affects the enthusiasm of farmers in participation in rural community cultural construction. Thus, we have to take measures to strengthen construction and effective use of rural cultural infrastructure.

Secondly, farmers have no enough knowledge in rural community cultural construction, so their autonomy of participation is relatively low. Due to the closed rural living means, limit of social connection and narrowness of the life sphere, farmers are seldom edified by modern cultural life, so their cultural life is relatively poor and their economy is relatively laggard, rarely paying attention to rural community cultural construction in their thought and having limited knowledge in community cultural construction. Furthermore, with negative effects of the petty-farmer consciousness and market economy, some farmers, especially those with low cultural level, mistakenly believe that they can acquire wealth even if they have no culture. Thus, they are lacking in the consciousness to learn culture and to participate in culture. This condition causes some farmers to lack the enthusiasm in participating in community cultural construction of farmers who have relatively low autonomy of participation.

Thirdly, the relatively low cultural quality of rural community residents restrains the ability of farmers to participate. The quality condition of rural community residents affects the participation ability of farmers. Currently, the cultural quality condition of rural community residents is unoptimistic. According to statistics of the fifth national population census, the illiterate population in rural areas accounts for $11.55 \%$ of those at the age of 15 and above. Among the rural population at the age of 6 and above, those with an educational background of primary school account for $46 \%$, those with an educational background of junior middle school account for $35.89 \%$ and those with an educational background of senior middle school and above account for $6.25 \%$. (Data from the fifth population census) The low cultural level of farmers causes farmers to rarely read books or journals in their daily life, so their knowledge is relatively poor and their ability to accept modern culture is relatively weak, let alone innovation of culture and development of culture. It can be seen, the low cultural quality of farmers at present restrains their ability to participate in rural community cultural construction. 


\section{Countermeasures to facilitate farmers' participation in rural community cultural construction}

In order for farmers to participate in development of rural community cultural construction, we have to take feasible and effective measures to enlarge farmers' participation and push forward community cultural construction.

Firstly, we ought to strengthen community education, improve the quality of farmers and intensify the enthusiasm and ability of farmers' participation. The condition of relatively low cultural quality among farmers is a major impediment factor for farmers' participation in community cultural construction, whereas the key to improve the quality of farmers is to develop education. We have to integrate community cultural education and information resources, vigorously develop rural education and set up perfect rural education system. In order to vigorously develop basic rural education, the key is to popularize and consolidate the nine-year compulsory education with emphasis. In the mean time, we have to vigorously popularize rural occupational education. We should take an initiative in bringing culture to the countryside and bringing technology into the countryside, integrate more knowledge of technology, law and market in cultural entertainment activities, enable rural farmers to learn more skills from those activities, really taste the peasant flavor of culture in the process of striving for a relatively comfortable life and to experience the value of culture, and stimulate the enthusiasm and creativity of farmers in rural community cultural construction.

Secondly, we have to enlarge funds investment and set up cultural facilities and occasions to furnish perfect material foundation for farmers' participation. Cultural facilities are the hardware for rural community cultural construction and are also the important material foundation for farmers to participate in community cultural construction. However, the key to cultural facilities is the problem of funds. Thus, we must extensively open the channel for funds sources and fully mobilize the enthusiasm of the country, collective and individuals. First of all, we should enlarge government investment vigor, adjust resource allocation, strengthen the public cultural service project construction led by the government, enhance the rate of coverage of rural broadcast television and network, speed up cultural information resource sharing project construction, pay attention to rural motion picture projection project and push forward "bringing technology, sanitation and culture to the countryside" and the construction of cultural projects for the benefit of the people, such as, rural book houses. At the same time, we have to give full play to the market mechanism, positively development rural cultural undertakings and cultural industry and offer funds support for rural cultural construction. Only in this way, can we speed up the pace of rural cultural facility construction, gradually improve the condition of laggard rural cultural construction and build perfect conditions for farmers to participate in rural community cultural construction.

Thirdly, we have to take an initiative in cultivating community cultural organizations and encouraging farmers to participate in community cultural construction. Positive cultivation of rural community cultural organizations can change the current situation of a few rural community cultural activities and sterile cultural life. To improve the abundance of farmers' cultural activities and satisfy farmers' demands on culture also helps to organize farmers to participate in community cultural construction, promote farmers' enthusiasm in participation and enhance the construction level of rural community culture. For example, ever since 2003 when Taizhou in Zhejiang Province started construction of rural cultural clubs, altogether 3282 standard cultural clubs have been set up, which have become the paradise for local farmers' leisure and recreation, knowledge learning, experience of advanced culture and propagandizing civilized local customs. (Note 1) In order to cultivate rural community cultural organizations, the first thing to do is to pay attention to explore local characteristic culture, set up different styles of community cultural organizations and hold characteristic cultural and artistic activities that farmers are delighted to hear and see. Then, we have to continuously enlarge cultivation of the team of rural cultural talents, attempt to set up a cultural backbone team that belongs to farmers themselves and furnish important talents resources for rural community cultural activities and community cultural organizations. For instance, in Wanggeda Village Wangzhuangzi Town Bazhou in Hebei, farmers show favor for acting in an opera and have automatically set up farmers' opera troupes. This village made an investment of 2 million Yuan to construct farmers' parks and a capacious and high theatrical stage to offer activity occasions for farmers' opera troupes. On this stage, four small opera troupes in this village take turns to have a performance. Theatre fans from all surrounding villages come here to listen to an opera and act in an opera. Since farmers have abundant spare-time cultural life, gambling and superstition have no market at all. (Geng Jiankuo, Lin Yuhong, Wang Guohui \& et al., 2007)

Fourthly, we may resort to urban culture and elegant culture to enhance rural cultural level and attract farmers to participate in community cultural construction. Ever since the reform and opening up in China, construction of rural community culture has had great development. However, compared with development of urban cultural construction, rural community cultural construction still lags behind, and is unable to satisfy cultural demands of 
farmers, which also affects enthusiasm of farmers to participate in community cultural construction. On the contrary, the holistic level of urban cultural construction is far higher than rural cultural construction in that its cultural facilities are quite complete and its cultural talents are quite concentrated who have accumulated abundant advanced experiences in terms of community cultural construction and can offer reference for rural community cultural construction. Thus, we have to make full use of urban cultural advances to enhance rural cultural level and push forward rural community cultural construction. We may turn to urban culture to play its irradiative function in rural culture, take an initiative in performing activities of "bringing culture to countryside" and "poverty alleviation of culture" so as to continuously enrich rural cultural battlefield, encourage urban cultural artistic practitioners to go deep to countryside and create more and better literature and artistic quality goods that reflect rural characteristics of the times and that farmers are delighted to hear and see, give full play to superiority of higher artistic colleges and universities in cultivation of talents and foster cultural talents for rural community. Through all the above feasible work, we have strengthened irradiative power and influential power of rural community culture and encourage farmers to take an initiative in participating in rural community cultural construction. On the basis of automatic organizing opera troupes for folk Chinese opera and cultural activities, the municipal government of Bazhou in Hebei Province resorts to urban culture and elegant culture to build regional cultural brand and enhance the cultural level of rural community opera. The local government made an investment of more than 50 million Yuan to establish Li Shaochun Memorial Hall (Great Theatre) and invited a batch of famous opera troupes and some well-known performance artists from Beijing and Tianjin to give a performance in the local theatre. "They have opera performance each month there". "On $28^{\text {th }}$ of each month when is the day of an opera performance, villagers from all towns of Bazhou and surrounding towns and counties come here to enjoy themselves". "We invite nation-level performance troupes to our village, so that the farmers may cost little or cost no at all to enjoy a high level performance. Therefore, their cultural life is enriched and their quality is enhanced. Our people are quite satisfied", said Huai Junling, the Curator of Li Shaochun Memorial Hall. (Geng Jiankuo, Lin Yuhong, Wang Guohui \& et al., 2007) Bazhou in Hebei Province has enhanced the opera cultural level of local rural farmers by inviting famous performers to give a performance, which also has improved the local community cultural construction level and promoted participation of farmers in community cultural construction.

\section{References}

Geng, Jiankuo, Lin, Yuhong, Wang, Guohui \& et al. (2007). Bazhou: Making Farmers Participate in Cultural System Construction. Guangming Daily, November 12, (5).

$\mathrm{Mu}$, Yifei. (2005). Farmers Participation --- Key to Enrich Rural Culture. Rural Economy, (2).

Population Census Office under the State Council, National Bureau of Statistics, Department of Population, Social, Science and Technology Statistics. (2002). Population Census Data of China in 2000 (Volume 1). Beijing: China Statistics Press, 623-632, 639.

Zhang, Guifang. (2004). Discussion on Cultural Construction of Rural Community at a Transitional Stage. Lanzhou Academic Journal, (5):213.

Note

Note 1. Cultural Paradise: Walking towards Ordinary People. [Online] Available: http://www.taizhou.com.cn/a/20090404/content_104402.html 